\title{
Isolation, identification, and antibacterial susceptibility testing of Moraxella catarrhalis isolated from the respiratory system of patients in northern Iran
}

\author{
Mina Eghbali (MSc) \\ Department of Microbiology, Fars \\ Science and Research Branch, Islamic \\ Azad University, Marvdasht, Iran \\ Majid Baserisalehi (PhD) \\ Department of Microbiology, Kazeron \\ Branch, Islamic Azad University, \\ Kazeron, Iran \\ Masood Ghane (PhD) \\ Department of Microbiology, \\ Tonekabon Branch, Islamic Azad \\ University, Tonekabon, Iran \\ Corressponding Author: Majid \\ Baserisalehi \\ Email: majidbaserisalehi@gmail.com \\ Tel: +989111936373 \\ Address: Department of \\ Microbiology, Kazeron Branch, \\ Islamic Azad University, Kazeron, \\ Fars province, Iran. Postal cod: \\ 7319846451 \\ Received: 2019/05/31 \\ Revised: 2019/08/10 \\ Accepted: 2019/11/20 \\ (c) (i) (2) \\ This work is licensed under a Creative \\ Commons Attribution 4.0 License.
}

\begin{abstract}
Background and Objectives: Moraxella catarrhalis is considered as an emerging pathogen and a new nosocomial infection agent. This study was conducted to isolate and identify M. catarrhalis from clinical samples (respiratory tracts) and assess them for antimicrobial susceptibility patterns.

Methods: In total, 280 samples were collected from patients with respiratory tract infection, and 120 samples were obtained from healthy individuals in the control group. The isolates were identified by phenotyping and genotyping methods, and their antibiotic susceptibility was evaluated using disk diffusion methods. The presence of $\beta$-lactamase and efflux pump activity were specified via phenotypic methods. Finally, Bro and acrA genes in the isolates were detected by PCR technique.

Results: The frequency of this bacterium was $9.64 \%$ (27 out of 200) in patients with respiratory tract infection and $4.16 \%$ (5 out of 120) in the control group. Although the isolates were resistant to penicillin, they had various responses against other antibiotics. The results obtained from molecular method showed that $90.6 \%$ and $84.3 \%$ of the isolates possessed Bro and acrA genes, respectively. There was a significant relationship $(\mathrm{P}<0.05)$ between the presence of Bro and acrA genes and antibacterial resistance to ampicillin, amoxicillin, cefazolin, cefuroxime, and chloramphenicol.

Conclusion: 0ur findings confirmed the existence of M. catarrhalis in patients with respiratory diseases and the high prevalence of antibiotic resistant genes in M. catarrhalis isolates. Therefore, timely diagnosis and successful treatment can play important roles in preventing their spread.
\end{abstract}

Keywords: Moraxella Catarrhalis, Respiratory Tract Infection, Drug Resistance, BLactamase

This paper should be cited as: Eghbali M, Baserisalehi M, Ghane M. [Isolation, identification, and antibacterial susceptibility testing of Moraxella catarrhalis isolated from the respiratory system of patients in northern Iran]. mljgoums. 2020; 14(3): 19-25. 


\section{INTRODUCTION}

Moraxella catarrhalis is an important pathogen and a common cause of otitis media, pneumonia, sinusitis, and conjunctivitis in infants, children, and the elderly. In adults, $M$. catarrhalis leads to the formation of chronic obstructive pulmonary disease (COPD) and pneumonia (1-4). This bacterium further contributes to the formation of respiratory tract infections with other pathogens such as Streptococcus pneumonia and Haemophilus influenza (5-7). To detect this important infection agent, standard culture techniques and phenotypic tests can be employed. However, the cultivation of pharynx, sputum, sinus, and ear discharge is not routinely performed in medical diagnostic laboratories; therefore, the treatment of upper and lower respiratory tract infections is completely experimental and targeted against three main pathogens, namely $M$. catarrhalis, $H$. influenzae, and S. pneumonie (8). The response to standard antibiotic treatments has changed, and the prevalence of antibiotic resistance has reached a dangerous level in many treatment centers (9). Different methods make use of bacteria to protect the harmful effects of antibiotics. One of the most important mechanisms utilized in Gramnegative bacteria against $\beta$-lactam antibiotics is the production of $\beta$-lactamase enzymes which deactivate these antibiotics through the hydrolysis of the $\beta$-lactam ring (10). Because most of the isolated M. catarrhalis strains are capable of generating $\beta$-lactamase owing to the presence of the Bro gene, the bacteria are resistant to $\beta$-lactam antibiotics such as penicillin. On the other hand, studies have shown that the production of $\beta$-lactamases by $M$. catarrhalis has a modest effect on antibiotic susceptibility to other $\beta$-lactams and cephalosporins (11). $\beta$-lactams are among the most widely used antibiotics in the world; therefore, over the past two decades, creating resistance to these antibiotics has become a major medical challenge (12). Another antimicrobial resistance mechanism in $M$. catarrhalis is the presence of exiting pump. The efflux system is a highly important mechanism for antibiotic resistance, because it protects bacteria against different antibiotic classes such as $\beta$-lactams, quinolones, and aminoglycosides (13). There is not sufficient information concerning isolation, identification, antibiotic susceptibility, and the presence of antibiotic resistance genes in $M$. catarrhalis strains in patients with respiratory disease in northern Iran; accordingly, present study aimed to diagnose and appropriately treat the infections originating from this bacterium.

\section{MATERIALS AND METHODS}

In this descriptive cross-sectional study, 400 clinical samples, including pharynx's swab $(n=92)$, secretions of sinus $(n=85)$, ear discharge $(n=43)$, pulmonary secretions $(n=$ 60 ), and pharynx's swab of healthy individuals as control group $(n=120)$ were collected from April 2016 to March 2018. The patients were selected from among those referring to the infectious wards of the public hospitals in the cities of western Mazandaran province in the north of Iran (Noshahr, Tonekabon, and Ramsar) following diagnosis by specialists. The study was approved by the National Ethics Committee for Biomedical Research (Code of Ethics: IR.IAU.TON.REC.1397.022), and written informed consent was obtained from all participants. The samples were transferred to laboratory and subjected to microbiological analysis. To perform microbiological analysis, each sample was cultivated on the blood agar (Merck-Germany) and incubated at $37^{\circ} \mathrm{C}$. After $48 \mathrm{~h}$, all suspected colonies were picked up and phenotypically identified using Gram stain (Zistroyesh-Iran), catalase, oxidase, DNase, and nitrate reduction tests, and fermentation of glucose, sucrose, and lactose (Merck-Germany). To verify the presence of M. catarrhalis colonies, the hockey puck test was applied with a wooden stick to push the colonies across the plate.

In this study, the antimicrobial susceptibility of $M$. catarrhalis isolates was determined by disk diffusion test. To carry out the test, each isolate was added into the sterile phosphate buffer saline, and its turbidity was adjusted to $0.5 \mathrm{McFarland}$ tube $\left(1.5 \times 10^{8}\right.$ cells $\left.^{\mathrm{mL}-1}\right)$. Afterwards, $100 \mu \mathrm{l}$ of the suspension was fully streaked on the Mueller-Hinton agar medium (Merck-Germany) and antibiotic discs (Padtan Teb-Iran): penicillin $(10 \mu \mathrm{g})$, ampicillin (10 $\mu \mathrm{g})$, amoxycillin $(25 \mu \mathrm{g})$, cefazolin $(30 \mu \mathrm{g})$, cefuroxime $(30 \mu \mathrm{g})$, cefepime $(30 \mu \mathrm{g})$, ceftriaxone $(30 \mu \mathrm{g})$, clindamycin $(2 \mu \mathrm{g})$, coamoxyclav $(20 \mu \mathrm{g})$, trimethoprim sulfamethoxazole $(1.2 \mu \mathrm{g})$, gentamicin (10 $\mu \mathrm{g})$, ciprofloxacin $(5 \mu \mathrm{g})$, tetracyclines (30 
$\mu \mathrm{g})$, azithromycin (15 $\mu \mathrm{g})$, chloramphenicol $(30 \mu \mathrm{g})$, and erythromycin $(15 \mu \mathrm{g})$ were placed on the medium and the plates were incubated at $37^{\circ} \mathrm{C}$ for $48 \mathrm{~h}$. The disc strengths and the zone size were interpreted in accordance with Clinical Laboratory Standard Institute (CLSI 2017) guidelines $(2,14)$.

The presence of $\beta$-lactamase enzyme and Extended-Spectrum $\beta$-Lactamases (ESBL) enzyme in antibiotic resistant isolates was determined through the use of the nitrosafin (Sigma-Aldrich-USA) and amoxicillin/clavulanic acid discs (Padtan TebIran), respectively (15). To investigate the presence of efflux pump in the isolates of $M$. catarrhalis, a phenylalanine arginine beta naphtyl amide (Merck-Germany) was used as chemical inhibitor. The cultures were placed under a temperature of $37^{\circ} \mathrm{C}$ for 24 hours; the growth inhibitory area was then measured using a millimeter ruler and reported as sensitive, resistant or semi-sensitive based on the CLSI 2017 guidelines (16). The molecular identification was carried out by DNA extraction of $M$. catarrhalis using a DNA extraction kit (Isogene- Russian). The purity of the extracted DNA was assessed based on the absorbance of the extracted DNA at 260 and $280 \mathrm{~nm}$ wavelengths using bio photometer (Eppendorf-Germany).
Specific primers generated by TAG Copenhagen (Denmark) were employed to amplify the $16 \operatorname{SrRNA}, B R O$, and acrA genes. Table 1 shows the primers utilized in the present study.

To conduct the molecular study, each reaction was performed in a total volume of $25 \mu 1$ containing $13 \mu \mathrm{l}$ of molecular biology-grade water (Sigma Aldrich Company LTD., USA), $2.5 \mu 1$ of $10 \times$ PCR buffer (Geneall, korea ), 1 $\mu 1$ of 10 pmol of each primers, $1 \mu 1$ of $10 \mathrm{mM}$ dNTPs (Geneall, korea), $0.5 \mu \mathrm{l}$ of smart taq DNA polymerase (Geneall, korea), $1 \mu \mathrm{l}$ of 50 $\mathrm{mM} \mathrm{MgCl} 2$ (Geneall, korea), and $5 \mu \mathrm{l}$ of DNA template. PCR amplification conditions on the thermocycler (Biorad-Germany) were as follows: $95^{\circ} \mathrm{C}$ for $5 \mathrm{~min}$, followed by 35 cycles of $95^{\circ} \mathrm{C}$ for $30 \mathrm{sec}, 55^{\circ} \mathrm{C}$ for $30 \mathrm{sec}(16 \mathrm{SrRNA}$ gene), $55^{\circ} \mathrm{C}$ for $60 \mathrm{sec}$ (Bro gene), $56^{\circ} \mathrm{C}$ for 60 sec $\left(\right.$ acrA gene), and $72^{\circ} \mathrm{C}$ for $60 \mathrm{sec}$, with a final extension at $72^{\circ} \mathrm{C}$ for $10 \mathrm{~min}$.

An aliquot of all PCR products was run on a $1.5 \%(\mathrm{w} / \mathrm{v})$ agarose gels (Merck-Germany) with a 100 bp DNA ladder (Fermentas, Germany) and electrophoresed at $75 \mathrm{~V}$ for 40 $\mathrm{min}$. The bands were visualized by use of safe stain and photographed by a UVtransilluminator (UV doc, England).

The statistical analysis of the experimental was done via SPSS version19.

Table 1. The specific primers of $16 S r R N A$, Bro, and acrA genes

\begin{tabular}{|c|c|c|c|c|}
\hline Genes & Primer name & $5^{\prime} \rightarrow 3^{\prime}$ & $\begin{array}{l}\text { PCR product } \\
\text { length }\end{array}$ & References \\
\hline \multirow[t]{2}{*}{ 16SrRNA } & $16 S r R N A-\mathrm{F}$ & TTGGCTTGTGCTAAAATATC & \multirow[t]{2}{*}{$140 \mathrm{bp}$} & \multirow[t]{2}{*}{17} \\
\hline & 16SrRNAR & GTCATCGCTATCATTCACCT & & \\
\hline \multirow{2}{*}{ BRO } & BRO-F & CTTGGCGATGTCTACACC & \multirow{2}{*}{$220 \mathrm{bp}$} & \multirow{2}{*}{$\underline{18}$} \\
\hline & BRO-R & AAGTTTGGCATTGACACG & & \\
\hline \multirow[t]{2}{*}{ acrA } & acrA-F & CGTGTTGCCGCCATTGAGACTT & \multirow[t]{2}{*}{$520 \mathrm{bp}$} & \multirow[t]{2}{*}{19} \\
\hline & acrA-R & GGGAACACAGCGCGTAAGGTCA & & \\
\hline
\end{tabular}

\section{RESULTS}

Of the 400 samples, 32 samples were positive for $M$. catarrhalis (8\%). Strains were identified using 16SrRNA gene amplification by PCR technique. The comparison of phenotyping and genotyping identification of the isolates showed that all molecular identifications confirmed our phenotyping identification. The occurrence frequency of this bacterium in the patients with pharyngitis, sinusitis, otitis media, and respiratory failure was $5.43 \%, 8.24 \%, 13.95 \%$ and $15 \%$, respectively. However, M. catarrhalis was isolated from five healthy individuals with a frequency of $4.16 \%$.

Therefore, this bacterium occurred relatively more in patients with respiratory failure. The results obtained from antibiotic susceptibility of the isolates revealed that all isolates were resistant to penicillin (100\%), but there were various responses to other antibiotics. The phenotypic examination revealed that all 
isolates $(100 \%)$ had $\beta$-lactamase enzymes.

The phenotypic analysis showed that all isolates had extended spectrum betalactamases. Furthermore, the phenotypic examination results of efflux pump in the isolates showed that after adding the chemical inhibitor to the environment, the antibacterial activity of various antibiotic groups (penicillins, cephalosporins, phenicols, and tetracyclines) increased.

The obtained data showed that although penicillin resistance did not change after adding the chemical inhibitor, it could indicate another resistance mechanism for this antibiotic; however, there was an increase in the resistance to ampicillin, amoxicillin, cefazolin, cefroxime, chloramphenicol, and amoxicillin-clavulanic acid. Moreover, after performing this test, the amount of resistance to ceftriaxone, cefepim, and tetracycline reached zero (Table 2).

The results showed that the resistance of the above antibiotics to $M$. catarrhalis isolates was dependent on efflux pump because the removal of the efflux pump reduced the diameter of the inhibition zone in this group of antibiotics.

Data presented in Table 2 are the average of three replicates and the values are the total percentage, $(n=32$ cases $)$

Based on the results, 29 isolates possessed Bro genes $(90.6 \%)$ while 27 strains had acrA genes (84.3\%).

Table 3 shows the association between the Bro gene and the resistance of isolates to various antibiotics. As shown, there was a significant relationship between this gene and resistance to ampicillin, amoxicillin, cefazolin, and cefuroxime $(\mathrm{P}<0.05)$.

Table 4 shows the relationship between the acrA gene in $M$. catarrhalis isolates and various antibiotics. As observed, there was a significant relationship between this gene and resistance to ampicillin, amoxicillin, cefazolin, cefroxime, and chloramphenicol $(\mathrm{P}<0.05)$.

Table 2. Antibiotic resistance patterns of M. catarrhalis against different antibiotics based on the CLSI 2017

\begin{tabular}{|c|c|c|c|c|c|c|c|}
\hline Antibiotic class & Antibiotic names & \multicolumn{3}{|c|}{ With no inhibitors } & \multicolumn{3}{|c|}{ With inhibitors } \\
\hline \multirow{5}{*}{ penicillins } & & $\bar{S}$ & $\mathbf{I}$ & $\overline{\mathbf{R}}$ & $\mathbf{S}$ & $\bar{I}$ & $\mathbf{R}$ \\
\hline & & n $(\%)$ & n $(\%)$ & n $(\%)$ & n $(\%)$ & n $(\%)$ & n $(\%)$ \\
\hline & penicillin & $0(0 \%)$ & $0(0 \%)$ & $32(100 \%)$ & $0(0 \%)$ & $0(0 \%)$ & $32(100 \%)$ \\
\hline & ampicillin & $2(6.2 \%)$ & $3(9.4 \%)$ & $27(84.4 \%)$ & $11(34.4 \%)$ & $6(18.7 \%)$ & $15(46.9 \%)$ \\
\hline & amoxicillin & $3(9.4 \%)$ & $3(9.4 \%)$ & $26(81.2 \%)$ & $14(43.8 \%)$ & $5(15.6 \%)$ & $13(40.6 \%)$ \\
\hline$\beta$-Lactam Inhibitor & $\begin{array}{l}\text { amoxicillin-clavulanic } \\
\text { acid }\end{array}$ & $28(87.5 \%)$ & $2(6.2 \%)$ & $2(6.2 \%)$ & $30(93.8 \%)$ & $1(3.1 \%)$ & $1(3.1 \%)$ \\
\hline \multirow{2}{*}{$\begin{array}{l}\text { non-extended spectrum } \\
\text { cephalosporins }\end{array}$} & cefazolin & $1(3.1 \%)$ & $3(9.4 \%)$ & $28(87.5 \%)$ & $1(3.1 \%)$ & $10(31.2 \%)$ & $21(65.7 \%)$ \\
\hline & cefuroxime & $1(3.1 \%)$ & $4(12.5 \%)$ & $27(84.4 \%)$ & $9(28.1 \%)$ & $6(18.8 \%)$ & $17(53.1 \%)$ \\
\hline \multirow{2}{*}{$\begin{array}{l}\text { extended spectrum } \\
\text { cephalosporins }\end{array}$} & ceftriaxone & $29(90.6 \%)$ & $1(3.1 \%)$ & $2(6.2 \%)$ & $32(100 \%)$ & $0(0 \%)$ & $0(\mathbf{0} \%)$ \\
\hline & cefepime & $28(87.5 \%)$ & $3(9.4 \%)$ & $1(3.1 \%)$ & $32(100 \%)$ & $0(0 \%)$ & $0(\mathbf{0 \%})$ \\
\hline aminoglycosides & gentamycin & $32(100 \%)$ & $0(0 \%)$ & $0(0 \%)$ & $32(100 \%)$ & $0(0 \%)$ & $0(0 \%)$ \\
\hline quinolones & ciprofloxacin & $32(100 \%)$ & $0(0 \%)$ & $0(0 \%)$ & $32(100 \%)$ & $0(0 \%)$ & $0(\mathbf{0 \%})$ \\
\hline folate pathway inhibitors & $\begin{array}{l}\text { trimethoprim/ } \\
\text { sulfamethoxazole }\end{array}$ & $27(84.4 \%)$ & $2(6.2 \%)$ & $3(9.4 \%)$ & $27(84.4 \%)$ & $2(6.2 \%)$ & $3(9.4 \%)$ \\
\hline lincosamides & clindamycin & $30(93.8 \%)$ & $2(6.2 \%)$ & $0(0 \%)$ & $30(93.8 \%)$ & $2(6.2 \%)$ & $\mathbf{0}(\mathbf{0 \%})$ \\
\hline \multirow[t]{2}{*}{ macrolides } & azithromycin & $29(90.6 \%)$ & $3(9.4 \%)$ & $0(0 \%)$ & $29(90.6 \%)$ & $3(9.4 \%)$ & $0(\mathbf{0 \%})$ \\
\hline & erythromycin & $26(81.3 \%)$ & $4(12.5 \%)$ & $2(6.2 \%)$ & $26(81.3 \%)$ & $4(12.5 \%)$ & $2(6.2 \%)$ \\
\hline phenicols & chloramphenicol & $17(53.2 \%)$ & $2(6.2 \%)$ & $13(40.6 \%)$ & $27(84.4 \%)$ & $2(6.2 \%)$ & $3(9.4 \%)$ \\
\hline tetracyclines & tetracycline & $29(90.6 \%)$ & $2(6.2 \%)$ & $1(3.1 \%)$ & $32(100 \%)$ & $0(0 \%)$ & $0(\mathbf{0 \%})$ \\
\hline
\end{tabular}

S: sensitive, I: Intermediate, R: resistance 
Table 3. The relationship between the presence of Bro gene and resistance to different antibiotics in M. catarrhalis isolates

\begin{tabular}{|c|c|c|c|c|c|c|c|}
\hline \multirow[t]{2}{*}{ Antimicrobial agents } & \multicolumn{3}{|c|}{ Bro +} & \multicolumn{3}{|c|}{ Bro - } & \multirow[t]{2}{*}{ P-value } \\
\hline & $S(\%)$ & $I(\%)$ & $R(\%)$ & $S(\%)$ & $I(\%)$ & $R(\%)$ & \\
\hline penicillin & $0(-)$ & $0(-)$ & $29(100)$ & $0(-)$ & $0(-)$ & $3(100)$ & -- \\
\hline ampicillin & $1(3.4)$ & $1(3.4)$ & $27(93.1)$ & $1(33.3)$ & $2(66.7)$ & $0(-)$ & 0.003 \\
\hline amoxicillin & $1(3.4)$ & $2(6.9)$ & $26(89.7)$ & $2(66.7)$ & $1(33.3)$ & $0(-)$ & 0.005 \\
\hline amoxicillin-clavulanic acid & $25(86.2)$ & $2(6.9)$ & $2(6.9)$ & $3(100)$ & $0(-)$ & $0(-)$ & 0.653 \\
\hline cefazolin & $0(-)$ & $1(3.4)$ & $28(96.6)$ & $1(33.3)$ & $2(66.7)$ & $0(-)$ & 0.001 \\
\hline cefuroxime & $0(-)$ & $2(6.9)$ & $27(93.1)$ & $1(33.3)$ & $2(66.7)$ & $0(-)$ & 0.002 \\
\hline ceftriaxone & $26(89.7)$ & $1(3.4)$ & $2(6.9)$ & $3(100)$ & $0(-)$ & $0(-)$ & 0.728 \\
\hline cefepime & $25(86.2)$ & $3(10.3)$ & $1(3.4)$ & $3(100)$ & $0(-)$ & $0(-)$ & 0.653 \\
\hline gentamycin & $29(100)$ & $0(-)$ & $0(-)$ & $3(100)$ & $0(-)$ & $0(-)$ & --- \\
\hline ciprofloxacin & $29(100)$ & $0(-)$ & $0(-)$ & $3(100)$ & $0(-)$ & $0(-)$ & -- \\
\hline $\begin{array}{c}\text { trimethoprim } \\
\text { sulfamethoxazole }\end{array}$ & $24(82.8)$ & $2(6.9)$ & $3(10.3)$ & $3(100)$ & $0(-)$ & $0(-)$ & 0.584 \\
\hline clindamycin & $27(93.1)$ & $2(6.9)$ & $0(-)$ & $3(100)$ & $0(-)$ & $0(-)$ & 0.819 \\
\hline azithromycin & $27(93.1)$ & $2(6.9)$ & $0(-)$ & $2(66.7)$ & $1(33.3)$ & $0(-)$ & 0.263 \\
\hline erythromycin & $23(79.3)$ & $4(13.8)$ & $2(6.9)$ & $3(100)$ & $0(-)$ & $0(-)$ & 0.530 \\
\hline chloramphenicol & $15(51.7)$ & $1(3.4)$ & $13(44.9)$ & $2(66.7)$ & $1(33.3)$ & $0(-)$ & 0.086 \\
\hline tetracycline & $26(89.7)$ & $2(6.9)$ & $1(3.4)$ & $3(100)$ & $0(-)$ & $0(-)$ & 0.728 \\
\hline
\end{tabular}

Table 4. The relationship between the presence of acrAgene and resistance to different antibiotics in M. catarrhalis isolates

\begin{tabular}{|c|c|c|c|c|c|c|c|}
\hline \multirow[t]{2}{*}{ Antimicrobial agents } & \multicolumn{3}{|c|}{ Efflux +} & \multicolumn{3}{|c|}{ Efflux - } & \multirow[t]{2}{*}{ P- value } \\
\hline & $S(\%)$ & $I(\%)$ & $R(\%)$ & $S(\%)$ & $I(\%)$ & $R(\%)$ & \\
\hline penicillin & $0(-)$ & $0(-)$ & $27(100)$ & $0(-)$ & $0(-)$ & $5(100)$ & --- \\
\hline ampicillin & $0(-)$ & $1(3.7)$ & $26(96.3)$ & $2(40)$ & $2(40)$ & $1(20)$ & 0.001 \\
\hline amoxicillin & $0(-)$ & $1(3.7)$ & $26(96.3)$ & $3(60)$ & $2(40)$ & $0(-)$ & 0.001 \\
\hline amoxicillin-clavulanic acid & $23(85.2)$ & $2(7.4)$ & $2(7.4)$ & $5(100)$ & $0(-)$ & $0(-)$ & 0.494 \\
\hline cefazolin & $0(-)$ & $1(3.7)$ & $26(96.3)$ & $1(20)$ & $2(40)$ & $2(40)$ & 0.002 \\
\hline cefuroxime & $1(3.7)$ & $0(-)$ & $26(96.3)$ & $0(-)$ & $4(80)$ & $1(20)$ & 0.010 \\
\hline ceftriaxone & $24(88.9)$ & $1(3.7)$ & $2(7.4)$ & $5(100)$ & $0(-)$ & $0(-)$ & 0.583 \\
\hline cefepime & $23(85.2)$ & $3(11.1)$ & $1(3.7)$ & $5(100)$ & $0(-)$ & $0(-)$ & 0.494 \\
\hline gentamycin & $27(100)$ & $0(-)$ & $0(-)$ & $5(100)$ & $0(-)$ & $0(-)$ & -- \\
\hline ciprofloxacin & $27(100)$ & $0(-)$ & $0(-)$ & $5(100)$ & $0(-)$ & $0(-)$ & -- \\
\hline $\begin{array}{c}\text { trimethoprim } \\
\text { sulfamethoxazole }\end{array}$ & $22(81.5)$ & $2(7.4)$ & $3(11.1)$ & $5(100)$ & $0(-)$ & $0(-)$ & 0.408 \\
\hline clindamycin & $25(92.6)$ & $2(7.4)$ & $0(-)$ & $5(100)$ & $0(-)$ & $0(-)$ & 0.708 \\
\hline azithromycin & $26(96.3)$ & $1(3.7)$ & $0(-)$ & $3(60)$ & $2(40)$ & $0(-)$ & 0.056 \\
\hline erythromycin & $22(81.5)$ & $3(11.1)$ & $2(7.4)$ & $4(80)$ & $1(20)$ & $0(-)$ & 0.623 \\
\hline Chloramphenicol & $12(44.4)$ & $2(7.4)$ & $13(48.1)$ & $5(100)$ & $0(-)$ & $0(-)$ & 0.028 \\
\hline Tetracycline & $24(88.9)$ & $2(7.4)$ & $1(3.7)$ & $5(100)$ & $0(-)$ & $0(-)$ & 0.583 \\
\hline
\end{tabular}

\section{DISCUSSION}

M. catarrhalis is the fifth most prevalent agent of respiratory tract infection following H. influenza, S. pneumonia, Klebsiella pneumonia, and Pseudomonas aeroginosa (2021). This bacterium is able to attach to cellular and mucous surfaces of the respiratory tract, leading to the formation of a biofilm (22-23). Several factors, including age, living conditions, health, environmental agents, and genetics play a role in $M$. catarrhalis infection (24).

In the present study, $M$. catarrhalis was isolated from $32(8 \%)$ samples, a finding similar to the results of khoramrooz et al.(9.5\%) and different from the results of Farajzadeh Sheikh et al.(3.6\% \%) and Sheikhi et al., $(42.7 \% \%)$ in other parts of Iran; This difference is probably attributed to the different sampling times and geographical locations (25-27).

Similar results have been reported in other parts of the world. For instance, the prevalence of $M$. catarrhalis was reported by Tamang et al.(6.9\%), Osagie et al.(4.75\%), Mazin et al.(3.75\%), Elrhman et al., (3.75\%), and Lu (11\%) (2017) (20, 28-31). The highest isolation rate of this bacterium belonged to patients with respiratory failure, otitis media, 
sinusitis, and pharyngitis. Of note, $M$. catarrhalis was isolated and identified with a lower prevalence in the control group.

The rapid increase in the antimicrobial resistance to $M$. catarrhalis has caused many concerns in developed and developing countries, hence the need for antibiogram testing to prevent treatment failure and control the infection (13). So far, many studies have been conducted on the drug resistance pattern of $M$. catarrhis isolated from clinical specimens.

The results of Kirby-Bauer test revealed the antimicrobial susceptibility pattern of $M$. catarrhalis isolates against different antibiotics, with the highest resistance to $\beta$ lactam antibiotics. The results of the current research are consistent with Krishna et al., Elrhman et al., Hsu et al., Ramadan et al., and Funaki et al. who also reported high resistance to penicillin and cephalosporin antibiotics (2, 30, 32-34).

On the contrary, the isolates were $100 \%$ sensitive to ciprofloxacin and gentamicin antibiotics. Therefore, they can be suitable antibiotics for the treatment of infections caused by $M$. catarrhalis isolated from the patients studied in this study. Sensitivity to gentamicin and ciprofloxacin was further delineated by Krishna et al., Gergova et al., and Akinjogunla and Eghafonano (2, 35-36).

Today, resistance mechanisms in bacteria occur in different ways, one of which is the production of $\beta$-lactamase enzyme (37). In the present study, phenotypic and PCR techniques were employed to specify the $\beta$-lactamase activity and presence of the Bro gene. Although $\beta$-lactamase activity was observed in all isolates, the presence of Bro gene in the isolates of $M$. catarrhalis by specific primers revealed that the gene existed in 29 isolates with a frequency of $90.6 \%$.

In a study conducted by Kadry et al., Mohager et al., and Shi et al. on the molecular detection

\section{REFERENCES}

1.Gupta N, Arora S, Kundra S. M. catarrhalis as a respiratory pathogen. Indian J Pathol Microbiol. 2011; 54(4): 769-71. doi: 10.4103/0377-4929.91496.

2. Krishna S, Sagarika S, Jeer M, Surekha YA, Shafiyabi S, Pushpalatha $\mathrm{H}$, et al. Prevalence and Antibiotic Sensitivity Pattern of M. catarrhalis in Patients with Lower Respiratory Tract Infections in a Tertiary Health Care Centre in India. Int J Curr Microbiol App Sci. 2016; 5(6): 72-78. of Bro gene from M. catarrhalis, $87 \%, 73.3 \%$, and $99.4 \%$ of the strains possessed Bro gene and were fully resistant against penicillin, ampicillin, and cefalutin (38-40).

Another antimicrobial resistance mechanism in $M$. catarrhalis is the presence of efflux pump. Efflux pumps are able to remove a wide range of antimicrobial compounds from the cell (13). In the present study, 27 (3.84\%) isolates had acrA gene. Moreover, resistance to penicillins and other antibiotics such as aminoglycosides, tetracyclines, and chloramphenicles can be due to the presence of a perfusion pump. Therefore, according to our results, azithromycin, cefotaxime, ceftriaxone, ciprofloxacin, tetracycline, trimethoprim sulfumethoxazole, and gentamicin are the only antibiotic alternatives for the treatment of $M$. catarrhalis infections.

\section{CONCLUSION}

M. catarrhalis was present in the samples of patients with respiratory infections. The high resistance incidence of most $\beta$-lactam antibiotics in the present study can be considered as a warning signal in the clinics. The presence of resistant genes against $\beta$ lactam antibiotics and efflux pump has been proven in most isolates. Resistance to various types of antibiotics is required in the treatment of $M$. catarrhalis infections, hence the necessity of conducting further research and reducing the use of antibiotics.

\section{ACKNOWLEDGMENT}

We are grateful to Dr. Jamshidi Kazemi, all employees of the Pasteur medical diagnosis laboratory of Tonekabon, and all patients who assisted us in conducting this research. The study was approved by the National Ethics Committee for Biomedical Research at Islamic Azad university Tonekabon branch (Code of Ethics: IR.IAU.TON.REC.1397.022), and written informed consent was obtained from all participants.

\section{CONFLICTS OF INTEREST}

None to declare.

\footnotetext{
3. Earl JP, de Vries SPW, Ahmed A, Powell E, Schultz MP, Hermans PWM, et al. Comparative Genomic Analyses of the $M$ catarrhalis Sero sensitive and Sero resistant Lineages Demonstrate Their Independent Evolution. Genome Biol. Evol. 2016; 8(4): 955-974. doi: 10.1093/gbe/evw039.

4. Liu YL, Xiao M, Cheng JW, Xu HP, Xu ZP, Ye S, et al. $M$. catarrhalis Macrolide-Resistant Isolates are Highly Concentrated in Two MLST Clonal Complexes-CCN10 and CC363. Front Microbiol. 2017; 8: 201. doi: 10.3389/fmicb.2017.00201.
} 
5. Murphy TF, Parameswaran GI. M. catarrhalis, a Human Respiratory Tract Pathogen. Clin Infect Dis. 2009; 49: 124-131. doi: 10.1086/599375.

6. Verhaegh SJ, Saarloos JA, Verbrugh HA, Jaddoe VW, Hofman A, et al. Determinants of $M$. catarrhalis colonization in healthy Dutch children during the first 14 months of life. Clin Microbiol Infect. 2010; 16(7): 992-7. doi: 10.1111/j.14690691.2009.03008.x.

7. Ramana BV, Chaudhury A. Antibiotic sensitivity pattern of $M$. catarrhalis at a tertiary care hospital. International Journal of Pharmacy \& Life Sciences. 2012; 3: 1805-1806.

8. Bernharda SSV, Aebi C. Molecular pathogenesis of infections caused by M. catarrhalis in children. Swiss Med Wkly. 2012; 142: w13694. doi: 10.4414/smw.2012.13694.

9. Shaikh, S.B.U., Ahmed, Z., Arsalan, S.A. and Shafiq, S. Prevalence and resistance pattern of Moraxella catarrhalis in community-acquired lower respiratory tract infections. Infect Drug Resist. 2015; 8: 263-267. doi: 10.2147/IDR.S84209.

10. Sheikh SO, Irfan S, Zafar A. B-Lactamase production and antimicrobial susceptibility pattern of $M$. catarrhalis isolates: report from Pakistan. Asian Pacific Journal of Tropical Medicine. 2014; 7: 228-231.

11. Verduon CM, KoolsSijmons M, vanderPlas J, Vlooswijk J, Tromp M, Dijk HV, et al. Complement resistant. M. catarrhalis forms a genetically distinct lineage within the species. FEMS Microbiol Lett. 2000; 184(1): 1-8.

12. Bonomo RA, Rice LS. Inhibitor resistance class A betalactamases. Frontiers in Bioscience. 2006; 4: 34-41.

13. Spaniol V, Bernhard S, Aebi C. M. catarrhalis AcrAB-OprM Efflux Pump Contributes to Antimicrobial Resistance and is Enhanced during Cold Shock Response. Antimicrob Agents Chemother. 2015; 59(4): 1886-94. doi: 10.1128/AAC.03727-14. 14. Bhattacharyya S, Singh S, Sarfraz A, Jaiswal NK, Kumar R, Kumar A, et al. Study of Antibiogram and Virulence Factors of M. catarrhalis from a Tertiary Care Hospital. Int J Med Res Prof. 2017; 3 (2): 236-38.

15. Wayne PA. Clinical and Laboratory standards institute Performance Standards for Antimicrobial Susceptibility Testing Twentieth informational supplement. Clinical and Laboratory standards Institute. 2015; 35(3): 73-128.

16. Barrero MAO, Pietralonga PG, Schwarz DGG, Silva A, Paula SO, Moreira MS. Effect of the inhibitors phenylalanine arginyl Bnaphthylamide (PAßN) and 1-(1-naphthylmethyl)piperazine (NMP) on expression of genes in multidrug efflux systems of Escherichia coli isolates from bovine mastitis. Res Vet Sci. 2014; 97(2):176-81. doi: 10.1016/j.rvsc.2014.05.013.

17. Hays JP. M. catarrhalis: A mini review. Journal of Pediatric Infectious Diseases. 2009; 4(3): 211-220. DOI: 10.3233/JPI2009-0167.

18. Schmitz FJ, Beeck A, Perdikouli M, Boos M, Mayer S, Scheuring $\mathrm{S}$, et al. Production of BRO $\beta$-Lactamases and Resistance to Complement in European M. catarrhalis Isolates. Journal of clinical microbiology. 2002; 40: 1546-1548. doi: 10.1128/JCM.40.4.1546-1548.2002.

19. Lalitagauri M, Deshpande H, Sader S, Thomas R, Fritsche $\mathrm{R}$, Jones N. Contemporary Prevalence of BRO $\beta$-Lactamases in M. catarrhalis: Report from the SENTRY Antimicrobial Surveillance Program (North America, 1997 to 2004). J Clin Microbiol. 2006; 44(10): 3775-3777.

20. Tamang MD, Makaju RK, Jha BK, Shivananda PG, Bhramadatan KN. Prevalence of M. catarrhalis infections of the lower respiratory tract in elderly patients. Kathmandu Univ Med J. 2005; 3(1): 39-44.

21. Anita KB, Fernandez N, Malli CS, Mallya S. The prevalence of $M$. catarrhalis in lower respiratory tract infections. J Clin Diagn Res. 2011; 5: 240-241.

22. Bullard BLS, Lafontaine ER. Hag directly mediates the adherence of $M$. catarrhalis to human middle ear cells. Infect Immun. 2005; 73(8): 5127-5136.
23. Slevogt H, Seybold J, Tiwari KN, Hocke AC, Jonatat C, Dietel S, et al. $M$. catarrhalis is internalized in respiratory epithelial cells by atrigger-like mechanism and initiatesa TLR2-andpartly NOD1-dependent inflammatory immune response. Cell Micro boil. 2007; 9(3): 694-707.

24. Heiniger, NS, Troller R, Vischer M, Aebi C. A reservoir of M. catarrhalis in human pharyngeal lymphoid tissue. J Infect Dis. 2007; 196: 1080-1087.

25. Khoramrooz SS, Emaneini M, Jabalameli F, Aligholi M, Saedi B. Frequency of Alloicoccus otitidis, Streptococcus pneumoniae, M. catarrhalis and Haemophilus infuenzae in children with otitis media with efusion (OME) in Iranian patients. Auris Nasus Larynx. 2012; 39(4): 369-373.

26. Farajzadeh Sheikh A, Ahmadi Kh, Nikakhlagh S. Detection of Streptococcus pneumonia and Moraxella catarrhalis in patients with paranasal chronic sinusitis by polymerase chain reaction method. J Chin Med Assoc. 2016; 79(8): 440-4. doi: 10.1016/j.jcma.2016.03.002.

27. Sheikhi R, Amin M, Rostami S, Shoja S, Ebrahimi N. Oropharyngeal Colonization with Neisseria lactamica, Other Nonpathogenic Neisseria Species and Moraxella catarrhalis Among Young Healthy Children in Ahvaz, Iran. Jundishapur J Microbiol. 2015; 8(3): 14813. doi: 10.5812/jjm.14813.

28. Osagie RN, Esumeh FI, Eyaufe AA, Momodu E, Adeleke G. Occurrence of $M$. catarrhalis amongst Children in a Primary Health Care in Ekpoma Nigeria. American Journal of Research Communication. 2013; 1: 97-101.

29. Mazin O, Mohager M, Mogahid M, El Hassan E. Molecular detection of BRO $\beta$-lactamase gene of $M$. catarrhalis isolated from Sudanese patients. Ann Trop Med Public Health. 2013; 6(4): 441-445.

30. Elrhman EMA, Ibrahim AK, Abdelhalim KA. Frequency of M. catarrhalis from Patients with lower respiratory tract infection in Khartoum state, Sudan. World Journal of Pharmaceutical Research. 2015; 4: 2286-2293.

31. Jiang LX, Ren HY, Zhou HJ, Zhao SH, Hou BY, Yan JP, et al. Simultaneous Detection of 13 Key Bacterial Respiratory Pathogens by Combination of Multiplex PCR and Capillary Electrophoresis. Biomed Environ Sci. 2017; 30(8): 549-561.

32. Hsu SFLY, Chen TL, Siu LK, Hsueh PR, Huang ST. Antimicrobial resistance of $M$. catarrhalis isolates in Taiwan. J Microbiol Immunol Infect. 2012; 45(2): 134-40. doi: 10.1016/j.jmii.2011.09.004.

33. Ramadan MO, Ibrahim IS, Shaheen AM, Ali VE. Significance of $M$. catarrhalis as a causative organism of lower respiratory tract infections. Egyptian Journal of Chest Diseases and Tuberculosis. 2016; 66(3): 459-464.

34. Funaki T, Inoue E, Miyairi I. Clinical characteristics of the patients with bacteremia due to $M$. catarrhalis in children: a case-control study. BMC Infectious Diseases. 2016; 3: 16-73.

35. Gergova R, Markovska R, Mitov I. Antimicrobial resistance and production of beta-lactamases in Bulgarian clinical isolates M. catarrhalis. Annals of Microbiology. 2009; 59: 169-172.

36. Akinjogunla OJ, Eghafona NO. Prevalence, haemolytic activities and fluoroquinolones susceptibility profiles of $M$. catarrhalis. Nature and Science. 2011; 9: 65-72.

37. Kageto Y, Katsumi A, Ryoichi S. Antimicrobial susceptibility to $\beta$-lactam antibiotics and production of BRO $\beta$ lactamase in clinical isolates of $M$. catarrhalis from a Japanese hospital. J Microbiol Immunol Infect. 2017; 50 (3): 386-389. doi: 10.1016/j.jmii.2016.08.003.

38. Kadry AA1, Fouda SI, Elkhizzi NA, Shibl AM. Correlation between susceptibility and BRO type enzyme of $M$. catarrhalis strains. Int J Antimicrob Agents. 2003; 22: 532-536. 39. Mohager MO, Hassan EIMM, Omer EIFA, Elmekki MA. Molecular detection of BRO $\beta$-lactamase gene of $M$. catarrhalis isolated from Sudanese patients. Annals of Tropical Medicine and Public Health. 2013; 6(4): 441-445.

40. Shi W, Wen D, Chen C, Yuan L, Gao W, Tang P, et al. $\beta$ Lactamase production and antibiotic susceptibility pattern of Moraxella catarrhalis isolates collected from two county hospitals in China. BMC Microbiol. 2018; 18(1):1217-1225. doi: 10.1186/s12866-018-1217-5. 